\title{
Comparing Notes: Collaborative Networks, Breeding Environments, and Organized Crime
}

\author{
Alejandro Hernández \\ Georgetown University School of Foreign Service, USA \\ ah342@georgetown. edu
}

\begin{abstract}
Collaborative network theory can be useful in refining current understanding of criminal networks and aid in understanding their evolution. Drug trafficking organizations that operate in the region directly north of Colombia's Valle del Cauca department and the "collection agencies" that operate in the Colombian city of Cali have abandoned hierarchical organizational structures and have become networked-based entities. Through the exposition of Camarinha-Matos and Afsarmanesh's business networking ideas, this chapter examines the similarities and differences between the application of collaborative networks in licit enterprises, such as small and medium enterprises in Europe, and how the networks might be used by illicit criminal enterprises in Colombia.
\end{abstract}

Keywords: Organized crime, Colombia, drug trafficking organizations, collection agencies, illicit criminal enterprises, collaborative networks.

\section{Introduction}

We should not underestimate the importance of national and transnational organized crime networks. In its most recent analysis, the United States National Intelligence Council noted that

Concurrent with the shift in power among nation-states, the relative power of various non-state actors-including businesses, tribes, religious organizations, and criminal networks - will continue to increase. Several countries could even be "taken over" and run by criminal networks. In areas of Africa or South Asia, states as we know them might wither away, owing to inability of governments to provide for basic needs, including security [1].

In light of the National Intelligence Council's Global Trends 2025 report, Juan Carlos Garzón's work on criminal networks in Colombia, detailed in his book Mafia \& Co., comes at a particularly critical time for policy-makers. If states are to get the upper hand on criminal networks, policy-makers need pertinent theoretical frameworks and applied research to understand what they are combating. Together with that of Luis Camarinha-Matos, Garzón's work on collaborative-networked organizations represents one such combination of theory and empirical research that can help us advance our understanding of criminal networks. 
I utilize Camarinha-Matos' work on collaborative networking theory and breeding environments as a theoretical framework through which I examine the phenomenon of the "collection agencies" described below. I will draw out the differences, from the point of view of collaborative-networked organization theory, between Colombia's post-Norte Del Valle cartel trafficking structures, also covered in Garzón's work, and the sort of networks that the collection agencies represent. The paper demonstrates how collaborative network and breeding environment theory can be useful in developing a new understanding in relation to networked criminal organizations.

I set out to examine Camarinha-Matos and Afsarmanesh's work on business networking in the spirit of the enterprise theory of organized crime. Nikos Passas provides us with a definition of the enterprise theory.

If the goods or services happen to be outlawed, then illegal enterprises will emerge to meet the demand. In this respect, there is no difference between conventional and criminal enterprises. Very often, all that changes when the business is illegal are some adjustments in modus operandi, technology and the social network that will be involved [2].

I attempt to draw parallels between the application of collaborative networks in licit enterprises and consider how the networks might be used by illicit ones. I begin by describing networks and apply the concept to Colombia's criminal networks. I then consider "collaborative networks" and "breeding environments", drawing on the business networking ideas of Camarhina-Matos and Afsarmanesh, and apply these to the Colombian case. I conclude that collaborative network theory can be useful in refining current understanding of criminal networks and aid in understanding their evolution.

\section{Colombia's Criminal Networks}

In Mafia \& Co., Juan Carlos Garzón presents us with a somewhat frightening proposal regarding the evolution of organized crime.

Es posible, que de la misma manera que acontece con los seres humanos, cuya esperanza de vida no ha dejado de crecer dese 1840, las organizaciones criminales perduren cada vez más en el tiempo, adaptándose a los cambios en las condiciones [de su entorno] [3].

Organized crime in Colombia seems to be presently undergoing one such adaptation. Garzón highlights a shift from rigid hierarchical organizational structures to more networked-based criminal organizations. He depicts a new kind of criminal organization, one where traditional hierarchical structures have been replaced with more horizontal configurations.

De organizaciones pesadas, y si se quiere burocráticas, que buscan monopolizar las economías ilegales, se ha pasado progresivamente a la configuración de células que se especializan en una parte de la cadena de producción o en un mercado especifico [como en de la protección]. El líder que lo manejaba todo, ya no existe. Ahora se adoptan formas de dirigencia colegiadas, que coordinan una compleja red de facciones locales, que se articulan alrededor de transacciones constantemente cambiantes, según dicte la oportunidad del momento [3]. 
Garzón provides two pertinent examples of these newer, networked criminal organizations. I begin with the smaller criminal groups that came to replace the now defunct Norte Del Valle cartel, and then consider the phenomenon of the collection agencies in Cali.

The Norte Del Valle cartel, once one of the most powerful in Colombia, largely disintegrated following the death or capture of its former leaders [3]. The various factions of the defunct Norte Del Valle cartel have been atomized into smaller organizations, and each of these now specializes in one aspect of the drug production process that former cartel leadership used to control [3].

The new organizations receive product from others down the supply chain, process it, and sell it to the next organization in the chain. A separate group of organizations provides security for all those groups involved in the production and processing. The cooperation amongst them, intermittent as it may be, has allowed them to continue producing and profiting from the Norte Del Valle cartel's former business.

We can see a similar shift away from hierarchical criminal organizations in the example of the collection agency phenomenon in Colombia. Although "collection agency" might conjure up the mental image of a creditor's office, it turns out it that these entities are in fact

Un conjunto de relaciones mediante las cuales son coordinadas distintas actividades criminales. [...] Las "oficinas de cobro" tienen una extensa red que logra establecer vínculos desde los carteles, bajando por las organizaciones sicariales, la delincuencia común, las pandillas [...] la "oficina de cobro" no debe de ser entendida como un lugar físico [3].

We can conceptualize the collection agencies as a networked organization that marshals the relevant criminal elements within a geographic area. The collection agencies in Cali link together the criminal community of the city, from the neighborhood gangs to the powerful assassin organizations. In some cases, they can exert such a large influence over the criminal underworld as to be able to impose a "tax" on the profits from all criminal activity within its area of influence [3]. Although it may not direct all criminal activity within the city, it clearly has influence over most of it. Garzón points out that collection agencies often maintain a group of assassins on their payroll to collect profits from a city's drug trade and enforce agreements among criminal elements within the city. Moreover, collection agencies can act as brokers, between the criminal underworld and citizens, to facilitate any assassination or other illicit service.

Whether through supply chains or linking the criminal elements of a city, the post Norte Del Valle cartel criminal organizations and the phenomenon of the collection agencies in Cali provide us with two clear examples of criminal organizations that rely more and more on networks. This begs the question; What can network theory tell us about these entities? Can we differentiate among them, and if so, how?

\section{Collaborative Networks and Breeding Environments}

Collaborative network and breeding environment theory holds the key to ascertaining the type of networks each of our two examples exemplify. Luis Camarinha-Matos and Hamideh Afsarmanesh's research on collaborative-networked organizations provides 


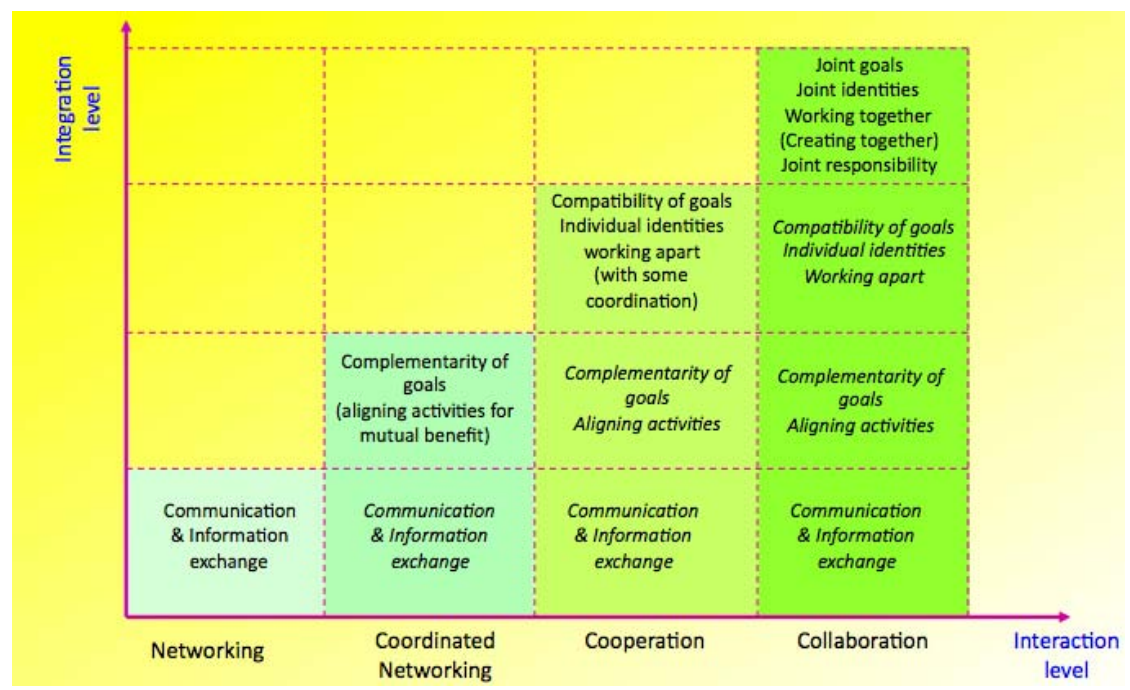

Fig. 1. Refining Concept of Collaboration As Advanced Interaction [4] [6]

useful, cutting-edge work on business networks. In this section, I present their ideas relevant to our interest in criminal organizations.

It is clear that the post Norte Del Valle cartel organizations and the phenomenon of the collection agencies represent some type of networked organization. Moreover, it seems that even though some of these organizations may compete with one another, or with other organizations, they also at points collaborate. In the case of the post Norte Del Valle cartel organizations, they collaborate in a drug production supply chain. Collaboration in relation to the collection agencies is somewhat different. The agencies themselves do not normally collaborate with other organizations, although they do create an environment that allows individuals under their purview to collaborate with one another. In both cases, the concept of collaboration is central to our understanding of the kinds of networks that these organizations represent. In order to better understand the concept of collaboration and its possible application to our understanding of Colombia's criminal networks, we will consider collaboration, a collaborative network, and a collaborative-networked organization.

Camarinha-Matos and Afsarmanesh define collaboration as

A process in which entities share information, resources and responsibilities to jointly plan, implement, and evaluate a program of activities to achieve a common goal. [...] [Collaboration] can be seen [...] as a process through which a group of entities enhance the capabilities of each other [...] Collaboration involves mutual engagement of participants to solve a problem together, which implies mutual trust and this takes time, effort, and dedication [4].

Camarinha-Matos and Afsarmanesh differentiate the concept of collaboration from that of networking, coordinated networking and cooperation [fig. 1]. Collaboration must not only have a purpose; it must also involve "parties that mutually agree to collaborate [...] that know each other's capabilities [...] and that share a [common] goal" [5]. 


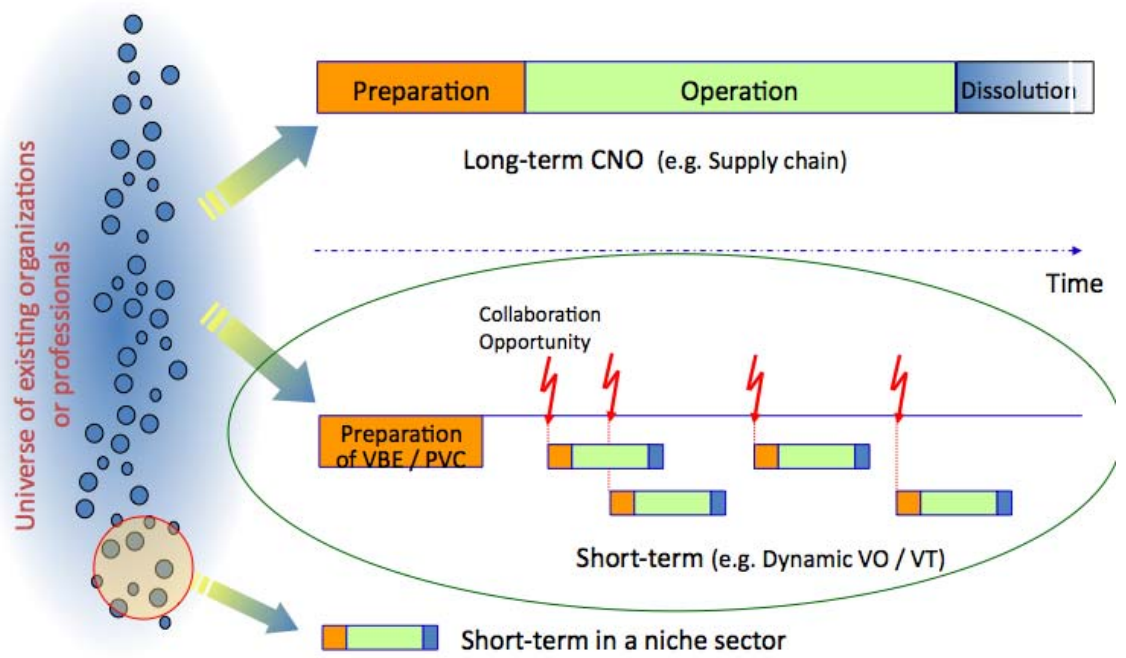

Fig. 2. Collaborative Networked Organization Formation Possibilities [6]

With collaboration defined we can consider a collaborative network. CamarinhaMatos and Afsarmanesh define a collaborative network $[\mathrm{CN}]$ as

A network consisting of a variety of entities [e.g. organizations and people] that are largely autonomous, geographically distributed, and heterogeneous in terms of their operating environment, culture, social capital and goals, but that collaborate to better achieve common or compatible goals, and whose interactions are supported by a computer network [4].

Furthermore, if it implies "some kind of organization over the activities of [its] constituents," [4] a CN can come to represent a collaborative-networked organization [CNO]. We can define a $\mathrm{CNO}$ as

A collaborative network possessing some form of organization in terms of structure of membership, activities, definition of roles of the participants, and following a set of governance principles and rules [4].

It is clear that the concept of a CNO imposes certain requirements upon the network. Moreover, collaboration, as it has been defined, remains at the core of the CNO. Camarinha-Matos makes it clear that developing the trust required to successfully establish and operate a CNO is not simple [5]. It takes time and resources. Knowing the capabilities of potential $\mathrm{CNO}$ partners can also present its own challenges. Given the costs and time involved in setting up a CNO, only those organizations that foresee long-term cooperation are likely to be willing to invest the capital and have the time necessary to establish one [Fig. 2] [5]. In such a case, the organizations involved would work towards the construction of what we can refer to as a long-term CNO [5]. 
In the past, European small and medium enterprises [SMEs], missed out on business opportunities that required collaboration with other SMEs because they did not have the resources or were simply not prepared to quickly set up CNOs with other SMEs [5]. In order to correct this situation, European SMEs have jointly developed frameworks that can aid them in the rapid creation of CNOs.

These frameworks can be referred to as long-term strategic networks, or breeding environments, and they emerged as the solution to the problems of SMEs in Europe. Camarinha-Matos and Afsarmanesh define these breeding environments as

A strategic alliance established with the purpose of being prepared for participation in collaboration opportunities, and where in fact not collaboration but cooperation is practiced among their members. In other words, they are alliances aimed at offering the conditions and environment to support rapid and fluid configuration networks, when opportunities arise [4].

When organizations come together, not in a long-term CNO such as in the case of a supply chain, but in the short-term with the explicit purpose of pursuing a single business opportunity, we refer to them as virtual organizations [Fig. 2] [4]. An example of a virtual organization would be that of an "organization" formed when multiple SMEs joined together to respond to a business opportunity. Breeding environments designed specifically to support the creation of virtual organizations [VO], are called virtual breeding environments [VBEs]. And we can define a VBE as

An association of organizations and a number of related supporting institutions, adhering to a base long-term cooperation agreement, and adoption of common operating principles and infrastructures, with the main goal of increasing their preparedness towards rapid configuration of temporary alliances for collaboration in potential Virtual Organizations. Namely, when a business opportunity is identified by one member [acting as a broker], a subset of VBE organizations can be selected to form a VO [4].

\section{Comparing Notes}

With these basic concepts from collaborative network theory, we can return to Colombia's criminal networks. First, let's examine the post Norte Del Valle cartel organizations. As we have previously mentioned, each organization that emerged as a result of the atomization of the cartel now plays a specialized role in a drug production supply chain. The overall structure of these organizations is analogous to a longterm $\mathrm{CNO}$, the kind that a supply chain would embody. Even so, if we examine the differentiation between the concepts of cooperation and collaboration, it quickly becomes evident that the post Norte Del Valle cartel organizations don't fully adhere to our concept of collaboration [Fig. 1]. It is difficult to see how these organizations, each with an armed security apparatus under its disposal and with shifting alliances, would have joint identities and joint responsibility.

On the other hand, they do share compatible goals and work with some level of coordination as cooperation would require. Moreover, we can now establish that the post Norte Del Valle cartel organizations are simply networked. Although they might not fully embody a collaborative network, they certainly seem to demonstrate the 
attributes of a cooperative network, which would point to more robust integration than simple networking would represent.

The phenomenon of the collection agencies presents a more difficult task. At first glance, the collection agencies would seem to be analogous to a breeding environment in the sense that they establish an environment that facilitates cooperation amongst different criminal elements within Cali. Even so, they do not fully embody to the concept of breeding environments as we have defined it. It is clear that the different criminal factions of Cali did not create the collection agencies in order to facilitate collaboration amongst themselves. Rather, the collection agencies were first established by the cartels to create money-laundering fronts and extort the various criminal activities of Cali [3]. Therefore, the collection agencies have evolved into a hybrid between a traditional hierarchical and a networked organization. The armed wing of the organization, which enforces agreements between the agency and other organizations, is fully under the purview of whoever controls the collection agency at a given point in time [3].

Even so, the vast network of criminals that the collection agency links is not directly under the agency's control. Moreover, the agency also allows for the cooperation between citizens and criminals by acting as a broker when the former requires an illicit service. Thus, breeding environment theory can help us conceptualize the collection agency's role in facilitating cooperation amongst criminal elements and between these elements and the general population. On the other hand, it is difficult to establish that the collection agencies represent an illicit counterpart to breeding environments, as these are utilized by licit SMEs around the world.

\section{Conclusions}

As we have seen, at the moment Colombia's criminal networks and its various criminal organizations do not fully embody collaborative-networked organizational structures. Yet, if one grants the usefulness of collaborative network theory, there is a broader question that arises. Namely, if illicit enterprises differ from their licit relatives only in their modus operandi, social networks, and technology employed, could they adopt collaborative-networked structures and create breeding environments to capture a broader range of business opportunities, ensure their long-term survival, and successfully evade law enforcement? The possibility seems likely and would resolve the ongoing tension between a desire to monopolize criminal markets, and a tendency towards ever more fragmented and networked criminal organizations. One can foresee a scenario where a VBE would be the criminal monopoly, and the various member criminal organizations would collaborate to take on all the criminal business in a particular city or region. If its knowledge base and operational tools were safeguarded from law enforcement and distributed to new organizations as they joined, a VBE would be longer lasting than any of the particular criminal organizations involved in it. Therefore, it is possible that the next step in the evolution of criminal networks might be closely linked with CNOs and VBEs.

Most importantly, the present analysis demonstrates the usefulness of CamarinhaMatos and Afsarmanesh's business networking ideas to social scientists attempting to understand networked illicit enterprises. To those of us involved in the study of organized crime - but not necessarily fluent in the language of networking - the development 
of these business networking ideas and their accompanying reference models represent an important knowledge base. By drawing on the new organizational dynamics of SMEs in Europe, we can develop new ways to conceptualize these illicit enterprises and work towards the creation of new typologies of organized crime groups. Thus aiding national and transnational efforts in data collection and organization on illicit networked and other organized crime enterprises.

Acknowledgments. I am enormously grateful to Georgetown University professors John Bailey and Daniel Sabet for their support and encouragement. Lindsay King of the University of Pennsylvania graciously shared her expertise and aided in the editing process. I would also like to thank professor Luis Camarinha-Matos for providing his diagrams for the paper. They proved to be an invaluable tool for illustrating the links between collaborative network theory and organized crime.

\section{References}

1. Intelligence Council, Nat.: Global Trends 2025, p. 1. National Intelligence Council, Washington (2008)

2. Passas, N.: The Rise of Transnational Crime. In: Presented paper, International Conference on Responding to the Challenges of Transnational Crime (1998); Leong, A.: The Disruption of Intrnational Organized Crime: An Analysis of Legal and Non-Legal Strategies, p. 15. Ashgate, Burlington (2007)

3. Garzón, J.C.: Mafia \& Co.: La Red Criminal en México, Brasil y Colombia, pp. 38-61. Planeta Colombiana, Bogotá (2008)

4. Camarinha-Matos, L., Afsarmanesh, H.: Collaborative Networks Reference Modeling, pp. 54-60. Springer, New York (2008)

5. Camarinha-Matos, L.: CNO Base Concepts: 1st ECOLEAD Summer School on Collaborative Networks, ECOLEAD Learning Environment. Video file, http://videolectures.net/ess06_matos_cbc

6. Camarinha-Matos, L., Afsarmanesh, H.: Collaborative Networks: Value Creation in Knowledge Society. Keynote paper, PROMALAT 2006, IFIP International Conference on Knowledge Enterprise-New Challenges (2006) 